\title{
ARTÍ́CULOS
}

\section{Mundo de la vida, ciudadanía y migraciones}

\section{World of life, citizenship and migrations}

Alcira B. Bonilla ${ }^{1}$ y Eduardo J. Vior ${ }^{2}$

\begin{abstract}
RESUMEN
En este trabajo los autores analizan el fenómeno migratorio y el reconocimiento y vigencia del derecho humano a la migración en torno a los tres aspectos enunciados en el título: la teoría y el mundo de la vida; la ampliación de la noción de ciudadanía y las relaciones posibles entre un tratamiento ampliado de la ciudadanía, y la participación política de las y los migrantes que dan por resultado la noción de "ciudadanías interculturales emergentes". Los desarrollos teóricos y epistemológicos se aplican al análisis del proceso que se da en la Provincia de Río Negro (Patagonia argentina), en la que conflictos característicos de "fronteras culturales" se entrelazan con aquéllos originados en las reacciones de minorías blancas trasplantadas ante la irrupción en la escena pública de comunidades de origen inmigrante. Esta contraposición entre las líneas de abordaje propuestas y un ejemplo típico, sirve para subrayar la importancia del clivaje entre las culturas y la necesidad de una perspectiva intercultural arraigada en el mundo de la vida, tanto para poder realizar un análisis teórico riguroso de esta dimensión del conflicto, como para elaborar propuestas tendientes a producir cambios en los imaginarios sociales y en las políticas públicas.
\end{abstract}

Palabras clave: Fenómeno migratorio, mundo de la vida, ciudadanía, perspectiva intercultural.

\begin{abstract}
In this work the authors analyse the phenomenon of migration, and the recognition and validity of the human right to migrate, in connection with the three aspects mentioned in the title: the theory and the world of life; extending the notion of citizenship; and the possible relations between a broader treatment of citizenship and the political participation of migrants, resulting in the notion of "emerging intercultural citizenships". The theoretical and epistemological developments are applied to an analysis of the process occurring in the Province of Río Negro (Patagonia, Argentina), in which typical conflicts of "cultural frontiers" are interwoven with those originating in the reactions of white minorities transplanted before the irruption on the public scene of communities of immigrant origin. This contraposition between the lines of approach proposed and a typical example serves to underline the profundity of the cleavage between cultures and the need for an intercultural perspective rooted in the world of life, in order to be able both to make a strict theoretical analysis of this dimension of the conflict, and to draw up proposals with the aim of producing changes in social imaginaries and public policies.
\end{abstract}

Key words: Phenomenon of migration, world of life, citizenship, intercultural perspective.

\footnotetext{
Doctora en Filosofía y Letras por la Universidad Complutense de Madrid, Licenciada en Filosofía, Universidad de Buenos Aires, Argentina. Alcira.beatriz.bonilla@gmail.com

2 Universidad Federal da Integração Latinoamericana, Foz do Iguaçu, PR, Brasil. ejvior@gmail.com. Doctor en Filosofía
} 
Siguiendo a É. Balibar y M. Foucault puede afirmarse que las migraciones contemporáneas constituyen "el hecho biopolítico mayor de nuestro tiempo". Cientos de millones de seres humanos se encuentran actualmente en movimiento por el mundo buscando un sitio donde construir una vida digna, otros tantos lo experimentaron hace una o dos generaciones y otros más se preparan a hacerlo. Sin embargo, la mayor parte de la producción científica y filosófica acerca de esta cuestión existencial de la vida humana sobre el planeta se realiza desde la posición del insider en las sociedades de arribo de las migraciones, tratándolas como un fenómeno ajeno y anormal y buscando protegerse de ellas mediante las normas y los códigos simbólicos que regulan el acceso a la comunidad de los asentados. Esta toma de posición enunciativa lleva a las y los investigadores a construir una dualidad entre el inmigrante que espera ante las puertas de las sociedades de acogida y el ciudadano que goza de todos los derechos, inclusive del de alterar a gusto los criterios para el ingreso a su comunidad.

La experiencia histórica muestra, empero, que las fronteras no son tan nítidas, que algunos individuos y grupos recién llegados a una comunidad pueden ser cooptados por los miembros de esta, mientras que a otros largamente asentados en el mismo territorio se los mantiene en sus márgenes por generaciones, que grupos hasta hace poco tiempo migrantes se han transformado en feroces guardianes del ingreso a las comunidades de arribo y viceversa, que quienes ostentaban alguna vez orgullosamente ese rol de repente se ven expulsados y lanzados a la búsqueda de un nuevo hogar. No existe, por consiguiente, un criterio objetivo para delimitar el mundo de las migraciones internacionales contemporáneas. Son inherentes al mundo cotidiano de la vida del sistema capitalista imperante y se las debe tratar como un fenómeno ubicuo y normal para no recaer en teorías sesgadas y parceladoras de la realidad.

A partir de la promulgación de la Ley argentina de Migraciones $\mathrm{N}^{\circ} 25.871$, en enero de 2004 , los autores de esta contribución han explorado en múltiples trabajos desde una aproximación intercultural a los derechos humanos las consecuencias y efectos del derecho humano a la migración proclamado en el Art. $4^{\circ}$ de esa norma ${ }^{3}$ (Bonilla 2006a, 2007b, 2008a, 2008b, 2008d, 2009b, 2010b, 2010c; Vior 2004c, 2005b, 2006a, 2007b, 2007c, 2008a, 2008d, 2009, 2010). El más trascendente parece ser su impacto sobre las relaciones de legitimación en el Estado contemporáneo. Resulta obvio inferir que, si la migración es un derecho humano, todo individuo o grupo tiene el derecho a permanecer en su lugar de origen, trasladarse por el mundo y asentarse donde le plazca para llevar una vida digna gozando de todos sus derechos humanos, incluidos los políticos. Ya no son los Estados nacionales quienes pueden seleccionar la composición étnica y cultural de sus poblaciones, sino los seres humanos, individualmente o en grupo, quienes tienen el derecho a decidir en qué Estado desean vivir. Esta inferencia tiene consecuencias no solo sobre la relación entre los recién llegados a una comunidad política y el Estado que la gobierna, sino también sobre el horizonte de posibilidades y expectativas de los migrantes, sobre las condiciones de vida de las poblaciones de acogida y sobre el carácter de la ciudadanía ejercida dentro de los Estados de salida y de llegada.

En este trabajo se propone una síntesis de los aspectos arriba enunciados para mostrar de qué modo el fenómeno migratorio y el reconocimiento y vigencia del derecho humano a la migración obliga a modificar las concepciones modernas de ciudadanía, todavía vigentes en los regímenes políticos actuales y en gran parte de la producción científica a pesar de sus sucesivas puestas en crisis tanto por la caída del mundo bipolar, como por el recrudecimiento de nacionalismos de vieja data y las presiones del mercado globalizador. Para el cumplimiento de tales objetivos, poco elaborados por los estudios migratorios contemporáneos, los autores señalan tres ejes básicos de su perspectiva discursiva: una posición teórica intercultural, una posición epistemológica interdisciplinaria y una convicción ético-política emancipadora.

"El derecho a la migración es esencial e inalienable de la persona y la República Argentina lo garantiza sobre la base de los principios de igualdad y universalidad" (Ley № 25.871, art. $4^{\circ}$ ). Esta Ley fue reglamentada por el Decreto № 616/2010. 
La propuesta teórica de los autores será desarrollada en torno de los tres aspectos enunciados en el título: la teoría y el mundo de la vida; la ampliación de la noción de ciudadanía y las relaciones posibles entre un tratamiento ampliado de la ciudadanía y la participación política de las y los migrantes, que dan por resultado la noción de "ciudadanías interculturales emergentes". Estos desarrollos teóricos y epistemológicos se aplicarán por último al análisis de una situación típica en la que conflictos característicos de "fronteras culturales" se entrelazan con aquellos originados en las reacciones de minorías blancas trasplantadas ante la irrupción en la escena pública de comunidades de origen inmigrante. En este trabajo se caracteriza a tal fin el proceso que se da en la Provincia de Río Negro (Patagonia argentina). Tal contraposición entre las líneas de abordaje propuestas y un ejemplo que puede considerarse típico sirve en la presente contribución para subrayar la importancia del clivaje entre las culturas y la necesidad de una perspectiva intercultural arraigada en el mundo de la vida tanto para poder realizar un análisis teórico riguroso de esta dimensión del conflicto como para elaborar propuestas superadoras tendientes a producir cambios en los imaginarios sociales y en las políticas públicas que muchas veces los reflejan.

\section{Teoría y mundo de la vida}

Los lamentos habituales de estudiosos que provienen del ámbito de las humanidades y las ciencias sociales acerca del lugar menor que la sociedad les reconoce y la función poco clara e incidencia escasa que adjudica a sus saberes respecto del bien común social (con la consecuencia de que tales académicos resultan postergados en el otorgamiento de subsidios, premios y cargos) reflejan un clima de malestar bastante generalizado que hace surgir un abanico de actitudes entre las de encierro elitista y otras de sometimiento a los poderes, sean estos políticos, religiosos o económicos. En tales debates prospera un clima de nostalgia que se alimenta de rememoraciones poco contextualizadas de las épocas presuntamente felices de Platón, Cicerón, Séneca, Voltaire o Hegel. Tornando la atención a contextos de mayor responsabilidad teórica, en estos se observan igualmente una cierta desazón expresada en polémicas sobre la especialización de las disciplinas y la compartimentación de los saberes -hoy puesta en tela de juicio desde diversas orientaciones epistemológicas-, la necesidad de abordajes complejos -como el aquí defendido-, y algunos revivals de las discusiones sobre el papel de los intelectuales y/o académicos en la sociedad que se cristalizaron hace unas décadas en las fórmulas del "intelectual orgánico" o del "intelectual libre". Contra estas voces paralizantes de quienes promueven la nostalgia o la desazón, tal vez convenga retornar a la figura filosófica de Edmund Husserl quien planteó la necesidad de reparar en el olvido manifiesto de la Lebenswelt ("el mundo de la vida") en las filosofías y las ciencias vigentes, y, con ello, en el descuido por parte de numerosos académicos y académicas de los problemas más acuciantes de la sociedad que son los de la vida cotidiana (lo que no indica un compromiso con intereses inmediatos), así como en el afán rigorista y erudito, cada vez más especializado, que caracteriza el cultivo de las disciplinas científicas y filosóficas. Habida cuenta de los análisis ya de larga data sobre las crisis de los saberes vigentes, parece entonces oportuno retrotraer las investigaciones de estos ámbitos del saber a la pregunta básica de la sabiduría andina por el Sumak Kawsay (el "buen vivir" o la "vida en plenitud") (Macas 2010: 14), tarea que se despliega fundamentalmente, aunque no solo, en el contexto concreto de la vida cotidiana del día a día. Para esto se deberían abandonar un tanto las distinciones lógicas y las oscuridades conceptuales, que además de legítimas muchas veces fascinan y entretienen a los intelectuales, y seguir la exhortación que hacía M. Merleau-Ponty a las y los filósofos coetáneos: "El primer acto filosófico tendría que ser volver al mundo vivido" (Merleau-Ponty 1945:69).

En efecto, el mundo de la vida cotidiano resulta paradójicamente mucho más complejo que la red de datos, conocimientos, experimentos, leyes, modelos y teorías en la que se mueven científicos y filósofos. Los seres humanos estamos situados en un mundo natural determinado (no inmutable) que se nos impone como dado y nos encuadra espacial y temporalmente junto con los demás vivientes, e integrados en un mundo sociocultural $y$, por ende, histórico; ambos inextricablemente fu- 
sionados en el mundo de la vida: "No solamente tengo un mundo físico, no vivo solamente en medio de la tierra, del aire y del agua, tengo a mi alrededor caminos, plantaciones, pueblos, calles, iglesias, utensilios, una campanilla, una cuchara, una pipa" (Merleau-Ponty 1945:399). En este mundo de la vida los seres humanos conocen y actúan intersubjetivamente y en comunidad con los otros seres humanos y vivientes; con ellas y ellos comparten, conocen, nombran, actúan y recuerdan el mundo de la naturaleza y el sociocultural e histórico. Es decir, en este mundo de la vida, además, la experiencia de cada ser humano y de cada grupo humano se articula, muchas veces conflictivamente, con la experiencia de los demás individuos y grupos. También es el contexto donde se instauran y determinan las biografías personales y las historias grupales. Siguiendo la inspiración husserliana, el dato más básico para el pensador es la experiencia de que los seres humanos viven en un mundo intersubjetivo, interactuando y comunicándose constantemente con los otros, en la conciencia de las semejanzas y de las diferencias. Para decirlo con palabras de P. Berger y de L. Luckmann: "Sé que mi actitud natural para con este mundo corresponde a la actitud natural de otros, [...] que también ellos organizan este mundo en torno del 'aquí y ahora' de su estar en él y se proponen actuar en él. También sé, por supuesto, que los otros tienen de este mundo común una perspectiva que no es idéntica a la mía. Mi 'aquí' es su 'allí'. Mi 'ahora' no se superpone del todo con el de ellos. A pesar de esto, sé que vivo con ellos en un mundo que nos es común. Y, lo que es de suma importancia, sé que hay una correspondencia continua entre mis significados y sus significados en este mundo" (Berger y Luckmann 1972:40-41). De modo consciente o inconsciente el mundo de la vida cotidiana constituye un modo de ver y vivir la realidad; en lenguaje cortazariano, una instalación que se vertebra en el aquí y ahora de la sociedad a la que cada ser humano y grupo pertenece que, por su parte, se da en una red de relaciones con los otros miembros de la sociedad y con los de sociedades diferentes.

Acentuando la dimensión cognoscitiva del mundo de la vida, en tanto ella es la que posibilita toda experiencia de conocimiento y la construcción misma del saber, una de las acepciones teóricamente más poderosas de la Lebenswelt brindada por Husserl es la definición que aporta en Erfahrung und Urteil: "mundo en el que siempre hemos vivido y que ofrece el terreno para toda función cognoscitiva y para toda determinación científica" (Husserl, 1954: 38; Husserl, 1980: 43). La mención de la definición husserliana en este trabajo no ocupa meramente un lugar erudito, sino que tiene una doble significación. Por un lado, volviendo nuevamente la atención al fenómeno migratorio (olvidado insistentemente en ámbitos como la filosofía y la ciencia política) se sostiene que este fenómeno ha integrado siempre, aunque con manifestaciones diversas, el mundo de la vida cotidiano, pero que ahora lo hace de maneras específicas y potentes provocando cambios sustantivos en los modos de entender y practicar la ciudadanía. Sin embargo, frente a este fenómeno contemporáneo que es parte de los cambios operados por el proceso de globalización en curso, estamos en un estado de desvalimiento y crisis teórica tales que, sin pretender transparencia absoluta, se impone la mediación de una interrogación de corte genético, tal como se deriva del texto husserliano citado. Siguiendo a Suzanne Bachelard en su interpretación de este pasaje de Husserl (Bachelard, 1957: 215), parece imponerse al filósofo y al científico social que intenten abordar el fenómeno migratorio una reducción de tipo genético que contribuya a suprimir sedimentaciones y mediaciones científicas que han llegado al límite de sus posibilidades y permita acceder a una experiencia deslastrada, más originaria y más rica, del fenómeno migratorio, para avanzar nuevamente en la investigación a partir de allí. Sin embargo, en este trabajo se pretende un retorno genético al mundo de la vida cotidiano y a los efectos de las migraciones contemporáneas en el mismo, entre otros, el de una modificación de las ideas más compartidas sobre la ciudadanía, como se dijo anteriormente, en una línea universalista que se aparta del Husserl más explícito. Aunque esta no sea una exposición metodológica que se aboque al tratamiento de estas diferencias parece oportuno retomar aquí los tres ejes básicos del locus enutiationis o perspectiva discursiva de la misma (posición teórica intercultural, posición epistemológica interdisciplinaria y convicción ético-política emancipadora) y explicitar el punto de vista de los autores sobre 
los dos primeros, en tanto el tercero resulta el supuesto de los parágrafos que siguen.

Respecto de la posición epistemológica y teórica intercultural, se señala brevemente que si bien existen diversas líneas y enfoques contemporáneos del pensamiento intercultural, y cantidad de estudios de diversos autores que toman buen cuidado en distinguir esta perspectiva de las diversas manifestaciones del multiculturalismo liberal (Bonilla, 2008c: 27-34), en este artículo se hace referencia al enfoque básico sostenido por los integrantes de la Escuela de Aachen (Bonilla 2005) y del Programa de Diálogo Intercultural Norte-Sur formado a partir de los años 90 por considerar que se trata de una propuesta amplia, en estado de elaboración avanzado, que sirve, además, de catalizador de otras vertientes del pensamiento intercultural y de la Filosofía y la Teología de la Liberación. Entre otros valores intrínsecos, hay que destacar que desde lo epistemológico, pero también desde lo éticopolítico, esta forma de pensamiento intercultural se hace cargo de la violencia ejercida por el colonialismo de los lenguajes y las teorías, habilitando así un tratamiento más amplio de temáticas como la del presente trabajo. Con seriedad se asume la existencia y persistencia de modos de colonialismo europeístas (castellano-español, portugués. francés, inglés, norteamericano, globalizado) que generaron una "condición colonial" que continúa hasta la fecha. La gravedad y el estilo de la "condición colonial" que afectó los países de América conquistados y colonizados por la Corona de Castilla se entienden mejor si a la consideración de los factores políticos, sociales y económicos que conformaron las diversas formas de dominación en estos quinientos largos años se suma la de los culturales y educativos que están en la raíz de la inferiorización, racialización y marginación de los pobladores originarios, de los esclavos importados de África y sus descendientes y también de los mestizos, criollos e inmigrantes, con el agravante de que esta América - a diferencia de Asia- fue imaginada por añadidura como "lugar vacío" por los conquistadores, siendo denominada posteriormente "el desierto" (logrado gracias al genocidio), el lugar de la "barbarie". Aquí se habla de "condición" y no de "situación" colonial para dar cuenta del fenómeno de la persistencia y aparición constante de nuevas formas e instrumentos de colonización y sobre todo de la identificación con los mismos que se produjo en las naciones luego independizadas de la metrópoli hispana durante todo su transcurso posterior. A partir de lo señalado puede reflexionarse sobre la necesaria condición colonial de la lengua, el pensamiento, las ciencias y las prácticas académicas en este lugar de América (la "ciudad letrada" investigada por Ángel Rama).

Tomando en cuenta la historia del colonialismo occidental este enfoque intercultural se presenta como opuesto a las prácticas del saber colonial y se propone poner de manifiesto la riqueza del pensamiento de aquellas culturas cuya dignidad cognitiva ha sido sustraída. Para ello cuestiona el prejuicio que excluye de la filosofía y de las ciencias modos de pensamiento que no condicen con los consagrados en las academias porque se los supone irracionales, mitológicos o religiosos o porque carecen de literatura canónica identificable como filosófica o científica, y se procura una reformulación del sentido y la tarea del pensar intentando un intercambio con saberes análogos a los occidentales presentes en las diversas tradiciones culturales del mundo. Respecto de América Latina, la perspectiva intercultural alienta la reconstrucción de esta historia tomando en cuenta la "violencia epistemológica trágica" sufrida por las ricas tradiciones de pensamiento prehispánicas o las que se fueron desarrollando luego, en general al margen de la academia (Fornet-Betancourt, 2008: 150-152).

Partiendo de la idea-fuerza de que toda teoría intercultural es un polílogo de razones plurales y contextuadas (Esterman 2006:46ss.) que se construye como un intercambio hermenéutico mutuamente interpelador, oyente $\mathrm{e}$ interpretativo (Fornet-Betancourt 2004c:256257), se esboza aquí una posición polilógica, superadora tanto de universalismos apriorísticos o dialécticamente teleológicos así como de los relativismos e instauradora de una "universalidad de horizonte" (Bonilla 2007a). Este modelo "fuerte" de pensamiento intercultural, en acuerdo con la Escuela de Aachen, puede concebirse según la metáfora de la "traducción" (Fornet-Betancourt 2003a:14). Siendo la traducción la operación humana que ha generado los mayores intercambios y pro- 
ducción de saber entre los seres humanos, con toda la ambigüedad y conflictos que siempre subyacen a los mismos, esta metáfora resulta de enorme interés, dado el carácter universal de la traducción (más allá de las discusiones ontológicas y éticas acerca de si la traducción es posible, como señala Umberto Eco, y con él varios autores más, “la gente traduce") (Eco $2008)^{4}$. Con esta metáfora pregnante se representan las teorías -o formaciones discursivas análogas- históricas y actuales que provienen de diversas matrices culturales como integrantes de polílogos de razones posibles entre discursos situados y contextuales de diversa índole. Desde esta perspectiva, los criterios de verdad no están dados a priori desde un logos etno y androcéntrico, como ha ocurrido con la filosofía y las ciencias europeas en el continente primero y luego en los países coloniales. Por esta razón, se sostiene la necesaria inclusión en el polílogo filosófico de las variables del poder y la dominación que en los países de América, Asia y África se determinaron como "condición colonial". Ellas deben impregnar hoy la filosofía y las ciencias sociales, incluida toda investigación sobre la ciudadanía, para evitar que las teorías sean nuevamente víctimas de la "violencia epistemológica" ejercida por el saber pretendidamente hegemónico que trata de imponer su paradigma. La pretensión de universalidad de cada uno de estos discursos, no convertida hegemónicamente ni en un a priori que preside toda producción teórica ni en un télos al que se deba tender unívocamente, por obra del diálogo ("polílogo") se manifiesta en el desideratum de la comunicación de una universalidad abierta, que bien podría denominarse "universalidad de horizonte" (Bonilla, 2010e), para no recaer en las dificultades de la gadameriana "fusión de horizontes".

Este objetivo de ir instaurando un polílogo entre razones contextuales e históricamente situadas ha levantado contra el pensamiento intercultural diversas críticas de esencialismo y fixismo culturales, señalando alguna de las más extremas e injustas que las definiciones de interculturalidad aludidas por los investigadores se sustentan en "[...] una concepción ahistórica, estática, homogénea y etnocentrista de la cultura" (Schmidt-Welle 2006:34). Frente a críticas de este tenor baste aclarar que, lejos de defender la idea de culturas como entelequias fijas y la de tradiciones culturales como dadas de una vez para siempre, esta perspectiva se basa, por el contrario, en la constatación de la movilidad constante de las mismas y por ello realiza un esfuerzo de desontologización o desculturización (Fornet-Betancourt 2009:41). En la misma línea se realiza una crítica de la categoría de "historicidad", tal como fuera defendida por la tradición europeísta de las teologías y filosofías de la historia (Fornet-Betancourt 2009:97). Más importante aún que estas refutaciones teóricas de tales visiones, al reconocer que no solo hay una pluralidad de historias, sino que la historicidad humana es temporalmente pluralista y que las historias múltiples no coinciden en un proceso de desarrollo simultáneo (FornetBetancourt 2009:99) el pensamiento intercultural otorga un lugar epistémico preferencial a la pluralidad de memorias de los pueblos de la humanidad, sobre todo las memorias del sufrimiento y de la liberación. En consecuencia, esta perspectiva epistemológica habilita críticas y estrategias teóricas que acompañen las prácticas de resistencia a la violencia con la que la pretendida globalización busca imponer sus imperativos uniformizantes. La interculturalidad como alternativa a la violencia, en definitiva, plantea esta traducción o polílogos de razones teóricas y prácticas como enriquecimiento exponencial del pensamiento en tanto da cabida a la auténtica posibilidad de contribuir a la generación de - parafraseando al filósofo Adolfo Achinte-, "filosofías de la re-existencia” (Achinte 2008: 14).

Un segundo supuesto de este trabajo es que su objeto complejo debe ser abordado de modo pluri e interdisciplinario superando dos ideas todavía habituales: la idea de que el tratamiento de este tipo de objetos puede realizarse como sumatoria de saberes disciplinarios y la idea de que la filosofía y la teoría política pueden constituir sus objetos de investigación y llevar a cabo la labor investigativa de forma autosuficiente 0 , al menos, mante-

Esta metáfora de la traducción remite al trauma del Descubrimiento y de acontecimientos coetáneos a este porque recuerda la espléndida actividad traductora de las escuelas de traductores (trasladadores, trujamanes, intermediarios) que generaron una situación de diálogo lingüístico y cultural embrionaria antes del Descubrimiento de América, frustrada por el totalitarismo lingüístico, cultural y religioso, también racismo, impuesto por la Corona de Castilla (Torre 1994: 29). 
niendo un diálogo externo y con fines meramente informativos con otras disciplinas. En lugar de contribuir a afinar la perspectiva de análisis, esta visión epistemológica más usual se rehúsa a tomar en cuenta los resultados de la investigación de otras ciencias humanas y sociales, reduce la complejidad de lo real a lo que cabe en moldes teóricos establecidos y se autolimita las posibilidades críticas. Así como ha sucedido en el campo de los estudios ambientales, cuya complejidad impulsó la búsqueda de modelos interdisciplinarios y dialógicos complejos de investigación (Funtowicz, Ravetz 1991), lo mismo se ha pensado en el campo de los estudios migratorios donde ya ha quedado probada la caducidad de los puntos de vista exclusivamente disciplinarios, como lo son el histórico, el demográfico, el económico, o la simple pluridisciplina, dada la multiplicidad y complejidad de variables a investigar, entre las cuales no resulta de menor importancia su vinculación con la cuestión de la ciudadanía. En consecuencia, en diversas publicaciones y congresos, particularmente el Congreso Argentino de Estudios sobre Migraciones Internacionales, Políticas Migratorias y de Asilo, celebrado en Buenos Aires a fines de abril de 2006, se asumieron y profundizaron las críticas a los enfoques exclusivamente disciplinarios y se subrayó la necesidad de encontrar marcos interdisciplinarios, en los que la filosofía ocupe un lugar no menor, que permitan realmente la construcción de una "caja de herramientas" adecuada para abordar la complejidad del fenómeno migratorio actual. Ha sido Stephen Castles, en 2001, quien con mayor agudeza hizo presentes críticas fundadas tanto a pensadores que, formados en disciplinas que jamás se habían ocupado del fenómeno migratorio, comenzaban a tratarlo como terra nullius, como a los estudiosos habituales de las migraciones. Entre las más severas pueden sintetizarse: 1) la imposibilidad de comprender la complejidad del proceso migratorio partiendo solo de áreas de conocimiento concebidas como autónomas (migración, etnicidad, racismo, multiculturalismo, comunidades trasnacionales, construcción identitaria, ciudadanía); 2) la compartamentalización entre los discursos científico sociales y los correspondientes a políticas migratorias; 3 ) la adhesión inconsciente de los investigadores a modelos ideológicos de nación; 4) la adhesión a tópicos, opciones metodológicas y marcos teóricos estrictamente disciplinarios; 5) el enclaustramiento en los límites de un paradigma que no se revisa a partir de las situaciones históricas cambiantes (Castles, 2001). En suma, se trata de construir una nueva síntesis que acabe con los compartimentos metodológicos, regionales e ideológicos, pero una síntesis no forzosamente ecléctica y, por esto, no meramente pluridisciplinaria. De allí el esfuerzo de los autores de este trabajo por elaborar una propuesta que retome la iniciativa husserliana desde las perspectivas abiertas por el pensamiento intercultural (Bonilla 2007c).

\section{Ciudadanía, derechos humanos y migraciones}

La filosofía y la teoría políticas han tratado mayormente el problema de la ciudadanía de un modo sistémico que da cuenta de las condiciones y formas de su ejercicio, pero que en general no discute los criterios que rigen el acceso a la misma. De este modo, si bien hay actualmente en las ciencias sociales y la filosofía un consenso generalizado sobre la existencia de grandes sectores y grupos poblacionales que no disfrutan de la ciudadanía, falta una matriz conceptual que permita explicar al mismo tiempo las reglas de acceso y las de funcionamiento de la misma. Para construirla puede partirse de la caracterización provisoria de que la ciudadanía es un estatus que permite la presentación de demandas ante el Estado y la comunidad política por la falta de vigencia de derechos humanos. Como primer paso para aclarar esta idea conviene, empero, definir previamente qué se entiende en este texto por derechos humanos.

Existe mundialmente un consenso amplio de que los derechos humanos son universales, inseparables, innatos, inalienables, sistémicos y recíprocos (Fritzsche, 2004:16-19). Sin embargo, las diferencias aparecen al definir su universalidad. Para las corrientes predominantes se entiende por tal la extensión progresiva por el mundo de los códigos y convenciones desarrollados en la tradición liberal contractualista desde fines del siglo XVII. Para muchos autores, derechos humanos son simplemente los codificados en los documentos internacionales vigentes. Desde la perspectiva intercultural aquí sostenida (Bonilla 2005a, 2006a, 2006b; Estermann 2006; Fornet-Betancourt, R. 2003a, 2003b, 2004a, 2004b, 2004c, 
2005; Pannikar 2003; Sidekum 2003a, 2004; entre otros $)^{5}$ se critica esta concepción por su etnocentrismo. Entendiendo por derechos humanos solo los codificados en dicha tradición y bajo esa forma en especial, se niega que el resto de la humanidad tenga nociones de derechos inherentes al ser humano y/o que estos existieran antes de la Modernidad europea (Schissler, 2005).

Por el contrario, se sabe que todas las culturas del mundo se han organizado desde su inicio sobre por lo menos dos premisas: el respeto a la dignidad de la persona y el derecho de resistencia a la opresión. Ambas constituyen bajo diversas formas y diferentes combinaciones núcleos irreductibles omnipresentes (Fornet-Betancourt 2000a:11-22; Fornet, Sanddkühler 2001: 28-36). No obstante, todas las culturas están también animadas por tendencias opresivas. La tensión entre ambos atractores es la fuerza motriz de la historia. Constatar esta universalidad del conflicto entre emancipación y opresión implica reconocer la igualdad entre las culturas, suponiendo al mismo tiempo que los derechos humanos solo son universales como articulaciones culturales específicas que se repiten en todas las culturas. Por lo tanto, si cada cultura está animada por una tendencia emancipadora y una opresiva, debe ser teórica y prácticamente posible descifrar sus códigos culturales y establecer equivalencias con otras culturas, haciendo universales dichas tendencias. Estas equivalencias solo pueden establecerse mediante la traducción intercultural, pero teniendo presente que se realiza entre culturas dominantes poseedoras del discurso competente (Chaui 1981) y otras a las que se niega la competencia para emitir juicios. Además de establecer equivalencias, la traducción permite comparar entre los diversos desarrollos culturales, sistematizando repeticiones y diferencias entre las culturas, para sacar conclusiones generales sobre continuidades y variaciones así como sobre el sentido de los desarrollos en la historia de los derechos humanos. Por consiguiente no existe universalidad de los derechos humanos sino en su contextualidad. Esta constatación vale para las relaciones interculturales como para las intraculturales, ya que las culturas son construcciones hegemónicas con discursos dominantes y otros subordinados (Fornet-Betancourt 2000; Fornet-Betancourt, Sandkühler 2001).

Las culturas son comunidades de significación con valor en tanto den sentido a la vida de sus miembros (Abu-Laban 2002; Alfaro, Ansión, Tubino 2008). Como bajo la hegemonía de la ideología globalizadora ninguna comunidad puede satisfacer todas las búsquedas de sentido de sus integrantes, las culturas ofrecen hoy solo limitados horizontes de sentido. Esta crisis aumenta por la pérdida de legitimidad de los Estados nacionales, las comunidades de sentido más importantes de la Modernidad. Las formas culturales mixtas, negociadas, híbridas están a la orden del día (Benhabib 2006; Bhabha 2002). En el sistema mundial capitalista vigente desde hace medio milenio las relaciones entre las culturas están signadas por el predominio de una hegemónica con base en el Atlántico Norte. La hegemonía de la cultura occidental implica que los discursos de las subordinadas pierdan competencia. Esta relación de hegemonía dentro del sistema mundo se reproduce dentro de cada periferia silenciando y desautorizando los discursos de los grupos subalternos que se fragmentan, perdiendo coherencia y complicando aún más la traducción intercultural.

Con esta perspectiva se establece un continuo argumentativo entre la experiencia que las comunidades de origen inmigrante hacen de su vulnerabilidad y la forma en que presentan sus demandas por derechos humanos insatisfechos. El Estado nacional es la forma general de la soberanía y la legitimación desde el siglo XVIII, pero al mismo tiempo esta forma tiene vigencia bajo articulaciones específicas, o sea, que el Estado nacional es a la vez la forma más general y más específica de la dominación y la legitimación. En su articulación ${ }^{6}$ con los aparatos y las prácticas princi-

Desde una visión histórica de la ciencia política, el coautor de este trabajo ha hecho varias contribuciones en el campo de los derechos humanos como fundamento del orden político (Vior 2005a, 2006d, 2008a, 2008b, 2008c, 2008d), en los estudios sobre la nación (Vior 1991, 2005b, 2005c, 2006b) y en las investigaciones sobre la participación política de las comunidades de origen inmigrante (Vior/Manolcheva/Manjuk 2004a; ebd. 2004b; Vior 2004, 2006a, 2007b).

6. Gracias a los efectos que la referencia a la imagen nacional tiene sobre la configuración de los sujetos políticos y jurídicos deseables y aceptables (Vior 1991: Cap. 4). 
pales de la dominación y la legitimación esta forma nacional condiciona a la administración y la esfera política para que tiendan a desoír los reclamos de las comunidades de origen inmigrante por no ajustarse a las normas de los discursos reconocidos.

En los estudios sobre la ciudadanía se clasifican habitualmente tres etapas en su desarrollo: 1) La formativa, entre principios del siglo XIX y mediados del XX, caracterizada por el reconocimiento político-jurídico de los derechos civiles y políticos y el acceso cada vez más difundido a los derechos ciudadanos. 2) Con T.S. Marshall (1950) se añade a los derechos mencionados el concepto de ciudadanía social. Este proceso coincide con la expansión del Estado de Bienestar en los países centrales. En el final de esta etapa se incorporan diversas minorías, se abren las discusiones sobre multiculturalismo y se debate sobre la democracia deliberativa y participativa (Habermas 1989, 1996). 3) A partir de 1990 la Ciencia Política desplaza su interés hacia el tratamiento de la gobernabilidad, priorizando el funcionamiento de las instituciones sobre el estudio de la representatividad y legitimidad de los Estados. Particularmente la irrupción de los pueblos amerindios en la escena política continental y las migraciones internacionales masivas cuestionan actualmente los fundamentos de la forma predominante de ciudadanía monocultural vigente. En la medida en que estas minorías irrumpen en la escena pública, puede constatarse la imposibilidad de "incorporar" estos grupos a la ciudadanía monocultural. Es necesario entonces desarrollar complejos procesos de comunicación intercultural para multiplicar las formas de la ciudadanía, adaptándolas a sus nuevos miembros y haciéndolas mutuamente compatibles.

Si bien la migración es un fenómeno constante en la historia de la humanidad, los flujos migratorios actuales presentan rasgos particulares. Al hablar de migrantes en esta exposición, los autores se refieren particularmente a los migrantes pobres; el "pobre extranjero", como los denomina Fornet-Betancourt (Fornet-Betancourt 2003, 2004c). Con esta acepción, por un lado, se dejan fuera de consideración aquellas categorías de migrantes que no están denotados por la característica de la pobreza extrema; por otro, excediendo los límites jurídicos y técnicos de la clasificación, bajo ese rótulo aquí se incluyen también a refugiados y exiliados ${ }^{7}$. En síntesis, se intentará volver visibles algunos aspectos problemáticos de la condición migrante (y de los estudios referidos a ella) focalizando en un universo de millones de personas y miles de grupos que han debido abandonar su lugar de origen porque la existencia en Este se les tornó inviable. La constancia y visibilización de "nuevos" migrantes, sobre todo en las grandes ciudades, conduce a la ruptura del mito del "crisol de razas" y a la reconsideración crítica de las prácticas políticas fundadas en él, principalmente en los ámbitos de la justicia, la salud, la educación y el trabajo. En la situación actual de pluralidad real por la copresencia en casi todas las sociedades del mundo de grupos de origen diverso, se torna indispensable la deconstrucción de este mito y la propuesta de nuevas formas de entender esta pluralidad con el objeto de posibilitar formas más plenas de realización individual y modelos de convivencia más justos, como ha sido señalado antes. En razón de lo dicho, la coexistencia de individuos y de grupos migrantes de gran heterogeneidad, mayoritariamente pobres, en nuestras megalópolis y en vastas regiones de las naciones actuales, interactuando en múltiples relaciones dinámicas con las sociedades denominadas de acogida y entre sí, impone por su propio peso una revisión más completa de la noción de ciudadanía, en la que se incluya fuertemente la categoría de "ciudadanía cultural”, pero a la vez el carácter inestable, dinámico y abierto de las relaciones referidas.

Dependiendo de su capital material y simbólico y de las contingencias de su inserción en la sociedad de acogida estos grupos migrantes pueden prosperar, ascender socialmente y hacerse o no presentes en la esfera pública. Las investigaciones de campo realizadas por los autores ${ }^{8}$ han demostrado que la condición sine qua non para que las comunidades de origen inmigrante logren irrumpir en la

En la jerga técnica, los "refugiados" tienen un estatuto diferente, regulado por normativas específicas, y el término "exiliado" no es jurídico, sino político-cultural.

8 Entre 2002 y 2003 en la Universidad de Magdeburg (Alemania), entre 2004 y 2006 en la Universidad Nacional de La Matanza, en 2009 en la Universidad Nacional de Río Negro, y desde 2004, y continúan, en la Universidad de Buenos Aires. 
escena pública y presentar allí sus demandas, es la existencia de mediadores interculturales en condiciones de traducir las necesidades y demandas de estos grupos en materia de derechos humanos insatisfechos a los códigos de la cultura dominante, de modo que los mismos puedan ser comprendidos y se hagan negociables. Generalmente estos mediadores/ traductores son miembros de los grupos subalternos que reúnen un capital cultural variado con aptitudes comunicativas especiales y se encuentran en el lugar y momento que les permita asumir creíblemente dicha representación. Una vez alcanzado el estadio de la comunicación intercultural, la politización de las demandas del grupo subalterno depende de la habilidad de sus mediadores/traductores para presentarlas de modo creíble, como si fueran las de un grupo amplio de la población, así como para incorporarlas a la agenda política9. Sin embargo, para que esta presentación de demandas ante el Estado y la comunidad política adquiera estatus de ciudadanía, todavía deben cumplirse otras condiciones (según se observó en el párrafo dedicado a las etapas del desarrollo de la misma).

Para estudiar mejor la problemática escurridiza de los procesos migratorios se los suele dividir en etapas, cada una de las cuales ofrece conflictos particulares tanto desde el punto de vista objetivo como subjetivo (vale decir, en referencia a la/las subjetividad/es migrante/s) A las tres que reconoce la literatura especializada: emigración, inmigración y reconstrucción de los lazos con el lugar de origen (que puede suceder o superponerse con la etapa anterior), cabría añadir la etapa del tránsito, por demás difícil y riesgosa tal como lo muestran numerosos ejemplos cotidianos. En cada una de ellas, tanto la construcción como las modificaciones de la subjetividad migrante, como los diversos procesos y momentos que jalonan sus relaciones con la sociedad de acogida, incluidos la presentación de demandas por derechos y el reconocimiento de los mismos, ponen en relieve la tensión existente entre vulnerabilidad y autonomía, a punto tal que estas categorías, en principio procedentes de la ética, merecen un tratamiento preferencial y complejo, vale decir, interdisciplinario, con intervención de la sociología, la ciencia política, la historia, la antropología, etc. Para mostrar la pertinencia del empleo de las nociones referidas en esta investigación cabe señalar que tanto la categoría de "autonomía" como la de "vulnerabilidad" han ocupado gran espacio en los desarrollos teóricos sobre la subjetividad, la moralidad y la ciudadanía, si bien es a partir de textos de la segunda mitad del siglo XX donde el tratamiento de la vulnerabilidad asume un lugar central (Levinas 1978; Jonas $1995 ; 2000)$. En una publicación reciente la coautora de este trabajo ha subrayado el mantenimiento de esta tensión a lo largo de la historia del pensamiento occidental, sobre todo en su uso ético-político (Bonilla 2010 d). Por esta razón, y de manera ilustrativa, solo se hace referencia aquí a la relectura de los textos kantianos realizada por P. Ricoeur en tanto este logra vincular "autonomía" y "vulnerabilidad" en un marco de tensiones múltiples de enormes consecuencias para la ética y para el tratamiento de los cuestionamientos que plantean las sociedades actuales (Ricoeur 2001: 85-105). Sin renunciar a la consideración kantiana del ser humano como autónomo, puesto que solo la capacidad de darse a sí mismo racionalmente la ley lo habilita para obrar de modo verdaderamente moral, la reconstrucción ricoeuriana del discurso kantiano a partir de las dos vertientes que se manifiestan respectivamente en la Crítica de la Razón Práctica (la autonomía como nudo a priori de la libertad y la ley) y en ¿Qué es la llustración? (la autonomía como tarea de sujetos políticos que deben salir del estado de sujeción), señala que la autonomía se presenta de modo paradojal y como "idea-proyecto": "Porque el ser humano es por hipótesis autónomo, debe llegar a serlo" (Ricoeur 2001: 86) ${ }^{10}$. De este modo queda manifiesta una ampliación de sentido de la autonomía, que permite considerarla a la vez como la prerrogativa y el desideratum de un ser vulnerable. Ambos términos, vulnerabilidad y autonomía, lejos de oponerse,

\footnotetext{
$9 \quad$ Para un análisis preciso del modo en que la amplia coalición de organizaciones de derechos humanos, de inmigrantes y algunos parlamentarios logró entre 1999 y 2003 que la promulgación de la nueva ley migratoria argentina (que llevaría el $\left.\mathrm{N}^{\circ} 25.871\right)$ fuera incorporada a la agenda política, v. Bosse (2007:69-87). Este fue un caso paradigmático de intervención de estas minorías en la escena pública construyendo ciudadanía en un momento de crisis del sistema político.

10 Trad. de A. B.
} 
se componen entre sí: “[...] la autonomía es la de un ser frágil, vulnerable. Y la fragilidad no sería más que una patología, si no fuera la fragilidad de un ser llamado a ser autónomo, dado que siempre lo es de alguna manera" (Ricoeur 2001: 87). De esta forma la autonomía (poder o capacidad) es concebida bajo la metáfora de un triple haz que se despliega en el poder de decir, en el poder de obrar sobre el curso de las cosas y de ejercer influencia sobre los otros protagonistas de la acción y en el poder de hacer una narración inteligible y aceptable de la propia vida (puesto que la dimensión temporal nos es intrínseca), a los que debe agregarse el poder de considerarse a sí mismo como autor de los propios actos. Ahora bien, la reelaboración del concepto de autonomía planteada integra niveles de vulnerabilidad (no potencia, o potencia menor o disminuida) que se corresponden igualmente con aquella: el "no poder decir" (fuente de desigualdad básica, dado que lo distintivo del ser humano es el lenguaje), las fragilidades en el ámbito del obrar, que provienen del curso del mundo (enfermedades, envejecimiento, accidentes) o son infligidas por otros seres humanos, habida cuenta de la disimetría entre el agente y el receptor de la acción, y por último la incapacidad de conducir la vida de acuerdo con la idea de coherencia o identidad narrativa desde la perspectiva insustituible de la singularidad, vale decir, de ser autónomo en sentido pleno.

Dado este marco teórico, resulta posible el abordaje interdisciplinario del tema central. Como se señala en la publicación reciente a la que se hizo referencia un poco más arriba, los estudios migratorios dan amplia cabida a la consideración de diversos aspectos de la vulnerabilidad y de la autonomía de las personas y grupos migrantes. Respecto del tratamiento de la vulnerabilidad de las y los migrantes, cabe decir que en cada una de las etapas o estadios de la migración dicha vulnerabilidad puede ser considerada desde dos puntos de vista: un punto de vista subjetivo y otro objetivo. Según el primero (el subjetivo) podría intentarse una fenomenología de la subjetividad migrante que muestra la vulnerabilidad manifestándose como malestar o sufrimiento. Consecuentemente ello redunda en dificultades para el ejercicio consciente de la autonomía (empowerment), en la internaliza- ción de estilos de minorización, en problemas para la identificación cultural y social, etc., con elevados riesgos de anomia y, por consiguiente, de una caída cada vez mayor en la vulnerabilidad extrema. Partiendo en cambio de una perspectiva objetiva, que atiende a las normas y prácticas de la sociedad de acogida referidas a los y las inmigrantes, la vulnerabilidad (efecto de las mismas) puede ser tipificada como exclusión, la cual comprende un abanico de formas de trato discriminatorio por parte de las sociedades de acogida que pueden sintetizarse como conculcación en diversos grados de derechos fundamentales para el ejercicio de capacidades y funcionamientos de la existencia humana ((Nussbaum; Sen 1993:3), entre otras, la participación ciudadana plena, es decir, el ejercicio de todos y cada uno de los derechos humanos en su conjunto.

En esta línea el aporte del sociólogo J. Bustamante facilita la diferenciación entre una "vulnerabilidad estructural" y otra, derivada de la anterior, la "vulnerabilidad cultural". En los Estados nacionales modernos la vulnerabilidad estructural se genera en la diferencia existente en las relaciones con el Estado entre un nacional y un migrante. De esta diferencia surgen las desigualdades en el acceso a los recursos, tales como prestaciones sociales, educación, trabajo, etc., y se van convirtiendo en el criterio normativo de las relaciones sociales entre nacionales e inmigrantes. Tales diferencias de poder se incrementan por la presencia de la vulnerabilidad cultural derivada de elementos culturales con significados despectivos tales como estereotipos, prejuicios, racismo, xenofobia, ignorancia y discrimintación institucional con los que se tiende a justificar las diferencias de poder entre los nacionales y los extranjeros" (Bustamante 2007: 55). Considerada "a la Weber" como tipo ideal, la vulnerabilidad estructural sería la construcción teórica que representa el extremo de la desigualdad que caracteriza a los inmigrantes internacionales como sujetos de derechos humanos y puede definírsela como "carencia extrema de poder", en tanto la "vulnerabilidad cultural" se define como la justificación ideológica de la existencia y de la práctica de la condición de vulnerabilidad de los migrantes de la cual se deriva la impunidad para quienes violen los derechos humanos de aquellos. 
Diversos estudios sobre las demandas de derechos y la participación y representación política de las y los migrantes, hacen hincapié en su capacidad de ir adquiriendo poder (empowerment) justamente por la mayor asunción de autonomía (Benhabib 2005; Bonilla 2006a; Kymlicka, 2003). El filósofo S. Mezzadra, en particular, pone el acento en la autonomía de las y los migrantes, a partir de sus investigaciones críticas sobre las relaciones contemporáneas entre globalización, trabajo y ciudadanía. Sin subestimar las causas objetivas de la migración ni sus condiciones materiales y sociales, con la categoría básica de "derecho de fuga" este autor pretende subrayar una dimensión subjetiva de los procesos migratorios fuertemente ligada al ejercicio de elecciones personales. Así aplicada, la categoría de derecho de fuga concentra en la figura del migrante las contradicciones inherentes al ejercicio del derecho a la libertad de circulación, poniendo en evidencia la naturaleza política de las disputas sobre las migraciones. En vez de reducir las migraciones contemporáneas a las leyes de oferta y demanda, su tesis de la autonomía de las migraciones, que saca al migrante de su papel subordinado de víctima, toma en cuenta el excedente de prácticas subjetivas que se expresan en los movimientos migratorios en relación con las 'causas objetivas' que los determinan (Mezzadra 2005: 143-157), y, en consecuencia, es apta para dar cuenta de fenómenos económicos y sociales vinculados con la migración, tales como la constitución de redes trasnacionales, y para plantear desafíos a las políticas migratorias centradas en el concepto de integración. Coincidiendo con Mezzadra respecto del potencial creador y hasta revolucionario de las y los migrantes, en tanto que su presencia cuestiona las creencias y prácticas habituales de la ciudadanía, está lejos de la perspectiva aquí expuesta obviar la existencia de fortalezas y capacidades individuales y grupales de resistencia de quienes han debido migrar. Pero, a juicio de los autores de este trabajo, si bien el aporte de Mezzadra resulta valioso, en tanto pone el fenómeno migratorio en el corazón del capitalismo y señala las contradicciones y alternativas posibles a este, a la vez minimiza las heridas en el cuerpo y en la subjetividad migrantes, así como las dificultades que estas personas y grupos padecen para ser visualizadas y reconocidas como sujetos de derechos en los lugares de acogida y para el ejercicio de tales derechos (Bonilla 2009a).

Ejemplo: la politización de comunidades de origen inmigrante en la Provincia de Río Negro (Patagonia argentina)

En este punto se propone retomar las preguntas realizadas al inicio de esta contribución indagando cómo funcionan estas relaciones interculturales en el mundo de la vida y en la representación política mediante la presentación de un ejemplo que puede considerarse típico. En él se procura mostrar de qué modo las relaciones interculturales e intercomunitarias construidas en el mundo de la vida cotidiana pueden continuarse y expresarse en la comunidad política.

Por ser una provincia relativamente joven ${ }^{11}$, con un territorio sumamente extendido y una concentración muy desigual de la población ${ }^{12}$, la Provincia de Río Negro plantea especiales desafíos a la representatividad y gobernabilidad del Estado. Las características históricas, económicas, sociodemográficas y culturales de las diferentes regiones condicionan diferentes relaciones de hegemonía, modos de construcción de ciudadanía, de relación entre el Estado y la sociedad en general, de construcción de estatuidad, de articulación y representación de intereses, etc. Al mismo tiempo las oleadas de inmigración extranjera contemporáneas (chilenos y

\footnotetext{
11 Como todos los territorios indígenas del Chaco y la Patagonia, conquistados por el Estado argentino a fines del siglo XIX, Río Negro fue durante muchas décadas un territorio nacional gobernado directamente por el Poder Ejecutivo Nacional. Recién en 1957 adquirió el estatus de provincia y pudo comenzar a elegir a sus autoridades y representantes. Esta provincialización reciente dejó fuertes huellas en el Estado, en el régimen de grandes latifundios originados en la usurpación de la tierra indígena y en los hábitos culturales.

12 De acuerdo a datos de la delegación Viedma de la Dirección Nacional de Migraciones, en Río Negro viven actualmente 75.000 chilenos, 50.000 bolivianos, 5.000 paraguayos y pequeños grupos de otras colectividades extranjeras. A esta cifra deben añadirse las personas originarias de esos mismos países que han tomado la ciudadanía argentina y, por consiguiente, ya no figuran como extranjeros en las estadísticas, así como los hijos de los inmigrantes que, de acuerdo a la ley argentina, son argentinos por nacimiento. Se trata, por lo tanto, de una porción muy alta de la población provincial total, estimada para el año 2008 en unos 600.000 habitantes (DGEyC 2009).
} 
bolivianos sobre todo) registran patrones de asentamiento, inserción productiva, sociabilidad y capacidad asociativa muy diferentes entre sí y con los contingentes inmigrados en décadas anteriores. Si se considera la combinación entre la colonización blanca desde fines del siglo XIX con las sucesivas oleadas inmigratorias europeas e internas y el más reciente poblamiento por inmigrantes sudamericanos, pueden caracterizarse las poblaciones blancas de la Provincia de Río Negro como "pueblos trasplantados" (Ribeiro, Rodríguez Ozán, Pereira Gomes, 1992) que conviven con los pueblos indígenas y los descendientes de los inmigrantes sudamericanos prácticamente sin mezclarse. Numerosas regiones sudamericanas y de otros continentes comparten características similares. Estas configuraciones peculiares, en las que comunidades de origen europeo conviven en el mismo territorio con otras subalternizadas sin mezclarse, se denominan "fronteras culturales" (Caggiano, 2003; Gil Araujo, 2003; Grimson, 2000). A pesar de los imaginarios de los grupos involucrados, estos también interactúan en las "fronteras culturales", solo que bajo el signo de la negación mutua. La construcción del Otro cultural como una categoría residual permite a los colonos proyectar en las poblaciones indígenas la violencia que dio origen y sostiene la relación de dominación. La legitimación del Estado se da más por desplazamiento y condensación en la figura negativa del indígena que por representación. La violencia que signa este tipo de relaciones puede manifestarse públicamente en cualquier momento por su bajo nivel de simbolización. Ambas partes involucradas en esta relación quedan fijadas en la imagen inmóvil del Otro. El racismo reduce al mínimo la capacidad adaptativa de una comunidad.

Cuando en estos contextos irrumpen colectividades de origen inmigrante que, como la boliviana en la Provincia de Río Negro, demuestran un gran dinamismo, la capacidad de adaptar sus técnicas de producción y reproducción a las condiciones ambientales de la Patagonia, tienen éxito económico y social y comienzan a manifestarse en la escena pública, colapsa la cosmovisión racista. Gracias al violento sometimiento de los indígenas los blancos se habían convencido mayoritariamente de su superioridad y de la perfección de sus instituciones y costumbres. En tanto, la comunidad de origen boliviano, con inocultables rasgos fenotípicos amerindios, demuestra su superior capacidad adaptativa, la cultura trasplantada sufre una profunda herida narcisista que la desarticula. En esta situación se encuentra hoy la cultura dominante en la Provincia de Río Negro (Bandieri, 2001; Fabregat, 2004).

En Argentina hay pocos antecedentes de estudios sobre la construcción de ciudadanía desde los grupos provenientes de la inmigración latinoamericana. Existen sí numerosas investigaciones sobre los modos de articulación política de las inmigraciones europeas llegadas al país entre 1860 y 1930 que pueden servir de referencia comparativa para indagar bajo qué condiciones necesidades insatisfechas de grupos poblacionales excluidos se convierten en demandas y estas en demandas políticas que puedan conducir a la ampliación de la comunidad ciudadana de derechos (Devoto, Otero, 2003).

En el caso de Río Negro las investigaciones sobre los grupos procedentes de la inmigración de países limítrofes a la provincia se concentran en aspectos demográficos, históricos o de inserción en el ámbito productivo (Acuña et al., 1993; Aguilera, 2005; Bendini et al. 2005; Gomiz Gomiz 2008; Radonich, 2004; Trpin, 2004). En el contexto sociocultural descrito esta falta de conocimientos sistemáticos no puede llamar la atención. Sobre este triángulo de conflictos (Estado/mayoría blanca-colectividades de origen inmigrante-mapuches) no se encuentran investigaciones $\mathrm{y}$, sin embargo, en los pocos meses que estuvieron disponibles para la investigación de campo que aquí sirve de ejemplo (Vior, 2009), este sistema de relaciones aparece como el ordenador omnipresente de las relaciones culturales, políticas, sociales y económicas en la provincia.

El estudio referido arribó a la conclusión siguiente: la Provincia de Río Negro (probablemente toda la Patagonia argentina) sigue siendo regida por los colonizadores blancos como tierra de frontera en la que en su imaginario deben permanecer constantemente alertas ante eventuales irrupciones de los pueblos indígenas. Esta actitud de defensa armada tiene tres consecuencias importantes en la configuración del mundo de la vida cotidiana en la provincia: 
a) La ética económica de los colonizadores se orienta al pillaje, la expoliación de suelos y pobladores y el permanente reclamo por subsidios del Estado nacional. Prácticamente no existe cultura del trabajo. Más bien está mal vista ${ }^{13}$.

b) El racismo antiindígena ha tachado a los mapuches como "invasores chilenos", negándoles por consiguiente todo derecho de ciudadanía. Es más, con este estigma se les niegan también los derechos como pueblos originarios consagrados por la Constitución Nacional reformada en $1994^{14}$.

c) El pujante desarrollo de la comunidad inmigrante de origen boliviano, asentada en diversas zonas del valle del río Negro desde hace unos veinte años, y su inocultable ascenso social ponen en crisis los estereotipos racistas hegemónicos en la provincia $^{15}$. En efecto, para los blancos los bolivianos y sus descendientes son "indios", resultando en consecuencia inimaginable que tengan éxito económico, se adapten bien a las reglas de funcionamiento de una economía capitalista semicolonial y sean capaces de desafiar el racismo imperante presentando públicamente sus demandas y negociando de frente con las autoridades. Esta irrupción de un grupo inmigrante exitoso en una zona liminar caracterizada por el clima de enfrentamiento total entre blancos e indígenas ha desarticulado el discurso dominante y puesto en crisis la gobernabilidad de la provincia. Las principales consecuencias de este colapso son la crisis permanente de las finanzas públicas, el cambio periódico de las coaliciones dentro del gobernante partido radical y la autonomía política y operativa que ha adquirido la policía provincial, lo que lleva periódicamente a violaciones de los derechos humanos como el asesinato de los tres jóvenes del Barrio Alto de Bariloche a quienes dedicamos este texto.

Si el fenómeno migratorio es parte constitutiva del mundo de la vida cotidiana en las sociedades actuales, y si es posible reconocer estilos de vulnerabilidad derivados de la conculcación de derechos de las y los migrantes, así como estilos de autonomía que se manifiestan en modos exitosos de presentar demandas para obtener el reconocimiento y la vigencia de estos derechos, en modos alternativos del ejercicio de la participación y de la representación, en formas negociadas y cada vez más variadas y potentes de ciudadanía, hacia el final de esta contribución, como se ha señalado en algunos textos anteriores, puede plantearse una manera más inclusiva de definir y entender la ciudadanía que denominamos "ciudadanías interculturales emergentes".

Esta nueva denominación, que se enmarca plenamente en las intenciones de la perspectiva intercultural bosquejada páginas antes, es deudora igualmente de los desarrollos teóricos de Marilena Chauí sobre "ciudadanía cultural" y de los diversos planteos contemporáneos de "ciudadanías interculturales”. En efecto, a la atribución de importancia al derecho a la cultura, que hace Chauí, como constituyente del sistema de los derechos humanos $y$, por consiguiente, inescindible de una práctica democrática de la ciudadanía. Ella afirma de modo fuerte que a la "cultura de la ciudadanía" propia de las sociedades democráticas corresponde necesariamente una ciudadanía cultural, quedando así implicada la idea de que la cultura ha de ser entendida como derecho ciudadano, indivisible de los demás derechos, y de que el Estado debe garantizar y promover para todos los habitantes de su territorio el derecho de acceso a las obras ya existentes, el derecho a la creación (que incluye la producción de

13 Observación hecha durante las sucesivas entrevistas, por la lectura de los periódicos provinciales y locales, por los medios audiovisuales de la región y mediante el análisis del papel que los subsidios del Estado nacional cumplen en la vida de la provincia.

14 A la consolidación y difusión social de este estigma ha contribuido poderosamente la obra del antropólogo Rodolfo Casamiquela, fallecido en 2008. Sobre la vida y la obra de R. Casamiquela v. Diario de El Bolsón, BW, 12-06-07; Chang Díaz, 2009; Nativos del Sur, 2008; Unidad de Investigación de Arqueología y Antropología del Centro Nacional Patagónico (CENPATCONICET), 2005.

15 En una colaboración reciente, se hizo referencia a los trabajos de campo realizados por el Dr. E. Vior e integrantes de su equipo de investigaciones que dan cuenta de la incidencia de la participación política de este grupo migrante en los municipios locales (Bonilla, 2010d). 
la memoria social) y el derecho a participar en las decisiones sobre políticas culturales (Chauí, 2006). En cuanto a la aparición de la expresión "ciudadanías interculturales" ella hace referencia a la reactivación necesaria de la participación ciudadana que solo puede realizarse en contextos realmente interculturales y en el plano de la formación y de la transformación permanente de las subjetividades políticas y como vínculo con una comunidad determinada en contextos de globalización (González, 2007:39-85; Alfaro et al. 2008: 30). De todas maneras sostenemos firmemente que solo a partir del reconocimiento a la vez internacional, estatal y social del derecho a la ciudadanía cultural, se podría plantear un ejercicio efectivo y mutuamente enriquecedor de "ciudadanía intercultural.

¿Qué se pretende decir con ello? Al hablar de "ciudadanías interculturales emergentes" se entienden aquí nuevas formas de entender la ciudadanía, nuevas formas de comprender este ejercicio pleno de los derechos y de participar y de ser representado o de representar, por un lado. Por otro, si "emergencia" significa una situación de extremo peligro o conflicto, con el adjetivo "emergentes" se indica que lo puesto en jaque, lo asediado, lo que peligra, es justamente esta ciudadanía intercultural que viene brotando con fuerza en nuestras sociedades complejas y plurales. Una sociedad que no intente hacerse cargo de esta emergencia está destinada a vivir en la injusticia que significa la conculcación de los derechos humanos de gran parte de su población, con riesgo de crear enclaves o ghettos de población dominada, que, en definitiva, pasarán a ser nuevas fuentes de conflicto para un futuro no demasiado remoto y que pueden convertirse en pasto de prácticas genocidas, a las que la Argentina como otros países no ha sido inmune ni en el pasado reciente ni antes. Ya para terminar, los autores queremos plantear que solamente la consideración del "otro" cultural en nuestras ciudades y en nuestros vastos territorios como un bien a incorporar y no un peligro a conjurar o controlar resulta absolutamente indispensable para que podamos gozar de una ciudadanía plena, cada vez más poderosa y potente y, por lo tanto, cada vez más emancipada. La "ciudadanía intercultural emergente" propiamente dicha.

\section{Referencias bibliográficas}

ABU-LABAN, Y. (2002), "Liberalism, Multiculturalism and the Problem of Essentialism", en: Citizenship Studies, Vol. 6, № 4, pp. 459-482.

ACHINTE, A. (2008), "Prólogo. El acto creador como pedagogía emancipatoria y decolonial", en: Madrid de Zito Fontán, L.; Palermo, Z., Cuentan las culturas, los objetos dicen...Salta, Crisol Ediciones, pp. 11-14.

ACUÑA, M. et al. (1993), Evolución y Características actuales de los asentamientos de población en el medio rural. El caso de Mosconi, La Ribera, Chacra Monte y Paso Córdoba. Trabajo dirigido por Lic. Kloster, E. Depto. de Geografía Facultad de Humanidades UNCo. Mimeo.

AGUILERA, M. E. (2005), "Migración hacia la zona de producción frutícola del Alto Valle del Río Negro. Características de un mercado de trabajo regional durante la década del 90", en: VIII Jornadas Argentinas de Estudios de Población. Asociación de Estudios de la Población Argentina (AEPA). Tandil.

ALFARO, S; Ansión, J. y Tubino, F. (eds.) (2008), Ciudadanía intercultural. Conceptos y pedagogías desde América Latina, Lima, Fondo Editorial de la Pontificia Universidad Católica del Perú.

ARENDT, H. (1994), Los orígenes del totalitarismo, Barcelona, Planeta-Agostini, 2 volúmenes.

BACHELARD, S. (1957) La logique de Husserl. Étude sur Logique formelle et logique transcendantale, Paris, PUF.

BALIBAR, É. (2005) Violencias, identidades y civilidad. Para una cultura política global, Barcelona, Gedisa.

BANDIERI, S. (2001), Cruzando la cordillera... la frontera argentino-chilena como espacio social, CEHIR, Neuquén.

BENDINI, M., et. al. (2005), "Nuevos espacios agrícolas y migraciones estacionales: el Valle Medio del río Negro", en: V Jornadas Interdisciplinarias de Estudios Agrarios y Agroindustriales, UBA, Buenos Aires.

BENHABIB, S. (2005), Los derechos de los otros. Extranjeros, residentes, ciudadanos, Gedisa, Barcelona. 
BENHABIB, S. (2006), Las reivindicaciones de la cultura. Igualdad y diversidad en la era global, Katz Buenos Aires.

BERGER, P. y Luckmann, L. (1972), La construcción social de la realidad, Buenos Aires, Amorrortu.

BHABHA, H. (2002), El lugar de la cultura, Manantial, Argentina.

BONILLA, A. (2005), “El diálogo filosófico intercultural y el fenómeno migratorio: su tratamiento como 'traducción' en la 'Escuela de Aachen'”. Actas 1er Congreso Latinoamericano de Antropología, Rosario, CD-Rom, pp. 29-47.

BONILLA, A. (2006a), Autonomía moral entre limones y colectivos: las "mamacitas" bolivianas en Buenos Aires, en Ingrid Wehr (ed.) Un continente en movimiento: Migraciones en América Latina, Frankfurt a. M./Madrid, Vervuert/Iberoamericana, pp. 143-158.

BONILLA, A. (2006b), “La filosofía intercultural como traducción racional”, disponible en: http: / / www.ddhhmigraciones.com.ar/publicaciones/publicacioneshome.htm

BONILLA, A. (2007a), "Universalidad, ciudadanía y migración", trabajo expuesto en la Mesa redonda "El malestar en la ciudadanía y su problematización en la ética contemporánea", en: Il Congreso Internacional Extraordinario de Filosofía, San Juan - Argentina, 9 al 12-07-2007. Actas, en prensa.

BONILLA, A. (2007b), "Ética, mundo de la vida y migración”, en: R. Salas Astrain (ed.), Sociedad y Mundo de la Vida a la luz del pensamiento Fenomenológico-Hermenéutica actual, Santiago de Chile, Ed. UCSH, pp. 27-58.

BONILLA, A. (2007c), “Esbozos para un campo interdisciplinario. Filosofia intercultural y estudios migratorios", en: C. Lértora Mendoza (ed.), XIII Jornadas de Pensamiento Filosófico. Evaluación de las ideas filosóficas 1980-2005, Buenos Aires, FEPAI, pp.179-188.

BONILLA, A. (2008a), “El 'Otro': el migrante”, en: Fornet-Betancourt, R. (Hrsg.), Menschenbilder interkulturell. Kulturen der Humanisierung und der Anerkennung, Aachen, Verlagsgruppe Mainz in Aachen, pp. 366- 375.

BONILLA, A. (2008b), “El derecho humano a migrar y la transformación de la noción de ciudadanía”, en: Arué, Bazzano, D’Andrea (comp.), Transformaciones, prácticas sociales $e$ identidad cultural, vol. II, Proyecto CIUNT2007, Tucumán, pp. 773-788.

BONILLA, A. (2008c), “Imágenes de nación y ciudadanías interculturales emergentes", Guerci de Siufi, B. (comp.), Filosofía, cultura y sociedad en el NOA, San Salvador de Jujuy, EDIUNJu, pp. 27-34.

BONILLA, A. y Vior, E. (2008d), Informe final del programa de investigaciones sobre "Derechos humanos, migración y participación", San Justo, UNLaM, disponible en: www.ddhhmigraciones.com.ar

BONILLA, A. (2009a), "La insuficiencia teórica del derecho de fuga", en: Lértora Mendoza, C. (ed.), XIV Jornadas de Pensamiento Filosófico (Actas), Buenos Aires, FEPAI, pp. 189-198.

BONILLA, A. (2009b), “Ciudadanías Interculturales Emergentes", en: Seibold, J. (coord.), IV Foro Educativo Escuela ciudadana, Ciudad educadora, Florida, Grupo Calgary, pp. 165 171.

BONILLA A. (2010a), "Respuesta de la filosofía intercultural a algunos enigmas del multiculturalismo", en Bonilla, A. B. y Vior, E. J. (eds.), Derechos humanos, migración y participación. Biblos, Buenos Aires, e/p.

BONILLA, A. (2010b), “Ciudadanías Interculturales Emergentes y vigencia de los Derechos Humanos", en: Actas, La Travesía de la Libertad ante el Bicentenario. IV Congreso Interoceánico de Estudios Latinoamericanos, X Seminario Argentino-Chileno, IV Seminario del Cono Sur de Ciencias Sociales, Humanidades y Relaciones Internacionales, Mendoza, Universidad Nacional de Cuyo. CD-Rom.

BONILLA, A. (2010c), “El mundo cotidiano de la vida y las ciudadanías interculturales emergentes de la migración", en Fornet-Betancourt (Hrsg.) Alltagsleben: Ort des Austauschs oder der neuen Kolonialisierung zwischen Nord und Süd. Aachen, Wissenschaftverlag Mainz, pp. 211-234.

BONILLA, A. (2010 d), "Ciudadanías Interculturales Emergentes”, en: Bonilla, A. y Cullen, C. (dres.), La ciudadanía en jaque. problemas éticos políticos de prácticas conquistadoras de sujetos, Buenos Aires, La Crujía, 2010. 
BONILLA, A. (2010e), "Vulnerabilidade vs. autonomía", Passagens, Revista Internacional de História Política e Cultura Jurídica, Rio De Janeiro: vol. $2 \mathrm{~N}^{\circ}$ 4, Maio-Agosto, pp. 4-38.

BÖSSE, D. (2007), Das Menschenrecht auf Migration im argentinischen Migrationsgesetz - Zur Entstehung des argentinischen Migrationsgesetzes 25.871 und dessen Auswirkung auf nationaler wie internationaler Ebene, tesis de Maestría en Ciencia Política, Universidad de Magdeburg (Alemania), inédita.

BUSTAMANTE, J. (2007), "La migración de México a Estados Unidos; de la coyuntura al fondo" En: Defensor del Pueblo de Bolivia - OACDH, Octava Conferencia Internacional de Instituciones Nacionales de Derechos Humanos. Migración. El rol de las instituciones nacionales. Informe Final, Santa Cruz de la Sierra, Editorial El País, pp. 41- 57.

CAGGIANO, S. (2003), "Fronteras múltiples: reconfiguración de ejes identitarios en migraciones contemporáneas a la Argentina", en: Cuadernos del IDES, en: http//: www.ides. com.ar (PDF), Buenos Aires.

CHANG DÍAZ, G. (2009), "Rodolfo Casamiquela (1932-2008)", en: Andean Geology 36 (1): 147148. January, 2009.

CHAUI, M. (1981), Cultura e Democracia: O Discurso Competente e Outras Falas, São Paulo, Editora Moderna.

CHAUÍ, M. (2006), Ciudadania cultural, San Pablo, Fundación Perseo Abramo.

CONGRESO ARGENTINO de Estudios sobre Migraciones Internacionales, Políticas Migratorias y de Asilo 2006, Instituto de Investigaciones Sociológicas del Consejo de Profesionales en Sociología, Buenos Aires, (CD-Rom).

CULLEN, C. (Dir.) (2007c), El malestar en la ciudadanía, Buenos Aires, La Crujía, 2007.

DEVOTO, F y Otero, H. (2003), "Veinte años después. Una lectura sobre el crisol de razas y el pluralismo cultural y la historia nacional en la historiografía Argentina", en: Estudios migratorios Latinoamericanos, $\mathrm{N}^{\circ} 17$, CEMLA, Buenos Aires.

DIARIO DE EL BOLSÓN BW (2007), Entrevista: “Argentina: Historiador Rodolfo Casamiquela: 'Los mapuches son chilenos... no tienen de- recho sobre la tierra'”, 12-06, disponible en: http://www.bolsonweb.com.ar/diariobolson/ detalle.php?id_noticia $=5535$

DIRECCIÓN GENERAL de Estadísticas y Cálculos (DGEyC, 2009), La población de la Provincia de Río Negro, Viedma, DGEyC.

ECO, U. (2008), Decir casi lo mismo. Experiencias de traducción. Montevideo, Lumen.

ESTERMANN, J. (2006) Filosofía andina. Sabiduría indígena para un mundo nuevo. 2 ed. La Paz, ISEAT.

FABREGAT, E. (2004), Análisis demográfico de la Provincia de Río Negro, Primer informe, Gobierno de la Provincia de Río Negro, Mimeo, Viedma.

FORNET-BETANCOURT, R. (ed.) (2000), Menschenrechte im Streit zwischen Kulturpluralismus und Universalität, IKO-Verlag für Interkulturelle Kommunikation, Frankfurt a. M. / London.

FORNET-BETANCOURT, R. y Sandkühler, H. J. (ed.) (2001), Begründungen und Wirkungen von Menschenrechten im Kontext der Globalisierung. IKO-Verlag für Interkulturelle Kommunikation, Frankfurt a.M. / London.

FORNET-BETANCOURT, R. (2003a), Interculturalidad y filosofía en América Latina, Aachen, Wissenschaftsverlag Mainz in Aachen.

FORNET-BETANCOURT, R. (ed.) (2003b), Resistencia y solidaridad. Globalización capitalista y liberación, Madrid, Trotta.

FORNET BETANCOURT, R. (2004a), Crítica intercultural de la filosofía, Trotta, Madrid.

FORNET-BETANCOURT, R. (Hrsg.) (2004b), Interculturality, Gender and Education, IKO, Frankfurt a. M.

FORNET-BETANCOURT, R. (Hrsg.) (2004c), Migration und Interkulturalität. Wissenschaftsverlag Mainz in Aachen.

FORNET-BETANCOURT, R (ed.) (2005), Migración e interculturalidad. Desafíos teológicos y filosóficos, Aachen, Wissenschaftsverlag Mainz in Aachen.

FORNET-BETANCOURT, R. (2009), Tareas y propuestas de la Filosofía Intercultural, Aachen, Wissenschaftsverlag-Mainz. 
FOUCAULT, M. (1997), "Il faut défendre la société". Cours au Collège de France. 1976. Paris, Gallimard-Seuil.

FRITZSCHE, K. P (2004), Menschenrechte - Eine Einführung mit Dokumenten, Ferdinand Schöningh / UTB, Padeborn.

FUNTOWICZ, S.; J. Ravetz (1993), Ecología política. Ciencia con la gente. Buenos Aires, CEAL.

GIL ARAUJO, S. (2003), “Las migraciones en las políticas de la Fortaleza. Sobre las múltiples fronteras de la Europa comunitaria", en: Gil Araújo, S. y Dahiri, M. (eds.), Movimientos migratorios en el Mediterráneo occidental. ¿Un fenómeno o un problema?, Ayuntamiento de Córdoba, Córdoba, (31-58).

GIUSTINIANI, R. et al. (2004), Migración: un derecho humano. Ley de Migraciones $N^{\circ} 25.871$. Prometeo, Buenos Aires.

GOMIZ GOMIZ, J. (2008), “Migraciones, ferias nupciales y hogares en Río Negro“, en: $3^{\text {as J Jor- }}$ nadas de Historia de la Patagonia, San Carlos de Bariloche.

GONZÁLEZ, J. (2007) “Ciudadanía e interculturalidad”, en: González, J. (ed.), Ciudadanía y Cultura, Bogotá, Universidad Nacional de Colombia, Universidad del Valle, Tercer Mundo Ediciones, pp. 39-85.

GRIMSON, A. (comp.) (2000), Fronteras, naciones e identidades. La periferia como centro, Ed. CICCUS / La Crujía, Buenos Aires.

HABERMAS, J. (1989), Identidades nacionales y postnacionales, Tecnos, Madrid.

HABERMAS, J. (1996), Die Einbeziehung des Anderen. Studien zur politischen Theorie, Suhrkamp, Frankfurt a. M.

HUSSERL, E. (1954), Erfahrung und Urteil. Redigiert und herausgegeben von Ludwig Landgrebe. Zweite Auflage. Hamburg, Glaassen \& Doverts.

HUSSERL, E. (1980), Experiencia y juicio. Investigaciones acerca de la genealogía de la lógica. Redacción y edición de Ludwig Landgrebe, con un epílogo de Lotar Eley. Trad. J. Reuter; rev. B. Navarro, México, UNAM.

JONAS, H. (1995), El principio de responsabilidad, Barcelona, Herder.
JONAS, H. (2000), El principio vida. Hacia una biología filosófica, Madrid, Trotta.

KYMLICKA, W. (2003), La política vernácula. Nacionalismo, multiculturalismo y ciudadanía, Paidós, Barcelona.

LEVINAS, E. (1978), Autrement qu'être ou audelà de l'essence, Haag, Martinus Nihjoff.

MACAS, L. (2010), "Sumak Kawsay: La vida en plenitud”, América Latina en movimiento, $\mathrm{N}^{\circ}$ 452 (14-16).

MARSHALL, T.H. (1950), Citizenship and social class and other essays, Cambridge University Press, Cambridge.

MERLEAU-PONTY, M. (1945), Phénoménologie de la perception, Paris, Gallimard.

MEZZADRA, S. (2005) Derecho de fuga. Migraciones, ciudadanía y globalización, Madrid/ Buenos Aires, Traficantes de sueños/Tinta Limón.

NATIVOS DEL SUR (2008), “Murió el científico Rodolfo Casamiquela”, Blog, viernes 5 de diciembre de 2008, disponible en: http:// nativosdelsur.blogspot.com/2008/12/muri-elcientfico-rodolfo-casamiquela.html

NOTE N. Fornet-Betancourt, R.; Estermann, J. y Aerts, D. (eds.) (2008), Worldviews and Cultures. Philosophical Reflections from an Intercultural Perspectiva, Dordrecht, Springer.

NUSSBAUM, M. y Sen, A. (eds.) (1993), The Quality of Life, New York, Oxford University Press.

PANNIKAR, R. (2003), “Conferencia inaugural: tres grandes interpelaciones de la interculturalidad”, en: Fornet-Betancourt R. (coord), Interculturalidad, género y educación. Dokumentation des $\mathrm{V}$ internationalen Kongresses fur interkulturelle Philosophie.

RABADE ROMEO, S. (1999), Conocimiento y vida ordinaria. Ensayo sobre la vida cotidiana. Madrid, Dykinson.

RADONICH, M. (2004), Asentamientos y trabajadores rurales. Una historia y un presente en el Alto Valle del río Negro y del Neuquén, Tesis de Maestría en Sociología Rural Latinoamericana, FADECS, UNCo, Mimeo.

RIBEIRO, D.; Rodríguez Ozán, M. y Pereira Gomes, M. (1992), Las Américas y la civilización: 
proceso de formación y causas del desarrollo desigual de los pueblos americanos, Caracas: Biblioteca Ayacucho.

RICOEUR, P. (2001), Le Juste 2, Paris, Esprit.

SCHISSLER, JAKOB (2005), "Menschenrechte zwischen Univesalismus und Kulturrelativismus“, en: Landeszentrale für Politische Bildung Baden-Württemberg (Hrsg.), Menschenrechte, Der Bürger im Staat, 55. Jahrgang, Heft 1/2, Stuttgart, pp. 26-30.

SCHMIDT-WELLE, F. (2008), "Todo lo sólido se desvanece... en la cultura. Interculturalidad, transculturación, heterogeneidad y ciudadanía cultural", en: B. Potthast, J. Ströbele-Gregor y D. Wollrad (eds.), Ciudadanía vivida (in)seguridades e interculturalidad: ADLAF Congreso Anual 2006, Buenos Aires, Nueva Sociedad, pp. 29-43.

SIDEKUM, A. (2003), Alteridade e Multiculturalismo, Ed. Unjuí, Ijuí,

SIDEKUM, A. (2004), "Desafíos para la filosofía intercultural: cultura y poder", en: Actas, VI Corredor de las Ideas del Cono Sur, Montevideo, CD-Rom.

TORRE, E. (1994) Teoría de la traducción literaria. Madrid, Síntesis.

TRPIN, V. (2004), Aprender a ser chilenos. Identidad, trabajo y residencia de familias migrantes en el Alto Valle de Río Negro, Antropofagia-IDES, Buenos Aires.

UNIDAD DE Investigación de Arqueología y Antropología del Centro Nacional Patagónico (CENPAT-CONICET, 2005), "Sobre las Manifestaciones de Rodolfo Casamiquela”, Declaración, Puerto Madryn, 19 de septiembre de 2005, disponible en: Enlace Mapuche Internacional, http: / / www. mapuche-nation.org/espanol/ html/noticias/ntcs-249.htm

VIOR, E. (1991), Bilder und Projekte der Nation in Brasilien und Argentinien, tesis de Doctorado, Gießen, microfilmada.

VIOR, E. J. (2003a), "La inmigración boliviana en Buenos Aires: ¿un nuevo sujeto popular?”, ponencia presentada en el Congreso anual de la Asociación Alemana de Investigación sobre América Latina titulado Migraciones, celebrado del 13 al 15 de noviembre en Friburgo, Alemania.
VIOR, E. J. (2003b), "Verändert sich die Sicht der Menschenrechte von Kultur zu Kultur?", texto de la lección magistral leída el 27-5-03 en el marco del ciclo de lecciones magistrales Experiment Menschenrechte, Universidad de Magdeburgo.

VIOR, E. J. (2003c), “Die Wiederaneignung der historischen Erzählung als Alternative gegen die Globalisierungsideologie", en: http:// www.transforma-online.net, 6-10-03, texto de la ponencia presentada el 6-7-03 en Magdeburgo, Alemania.

VIOR, E.J.; Manjuk, V. y Manolcheva, S. (2004a), "The Politics of Otherness - Constructing the Autonomy of Political Subjects in the Migrant Minorities as a way of Reforming Western European Democracias", en: Consolidating Antiracism and Minority Rights: Critical Approaches, Institute for Human Rights, Åbo Akademi University, Helsinki, Finlandia.

VIOR, E.J. y Manolcheva, S. y Manjuk, V. (2004b), Bestandsaufnahme demokratischer Initiativen in der politischen Bildungsarbeit mit muslimischen Jugendlichen in Deutschland- Ein Forschungsbericht, en: Bundesministerium des Innern (Hg.), Extremismus in Deutschland, Berlín, Bundesministerium des Innern, pp. 316-337.

VIOR, E.J. (2004) "Migración y derechos humanos desde una perspectiva intercultural", en: R. Fornet-Betancourt (ed.), Migración e interculturalidad. Desafíos teológicos y filosóficos, Aachen, Wissenschaftsverlag Mainz in Aachen, pp. 109-117.

VIOR, E. (2005a), “¿Qué imagen de Nación se adecua mejor a la nueva población de Argentina?", Actas. VII Congreso de la Sociedad Argentina de Análisis Político (SAAP), Córdoba, 15 al 19 de noviembre de 2005. CD-Rom.

VIOR, E. (2005b), “Inmigración y democracia: ¿hacia una ciudadania argentina pluricultural?", Actas. $1^{\circ}$ Congreso Latinoamericano de Antropología, Asociación Latinoamericana de Antropología, Rosario, 11/15-07-05, CD-Rom.

VIOR, E. (2006a), “Los bolivianos en Buenos Aires fortalecen la democracia: derechos humanos, inmigración y participación democrática", en: I. Wehr (ed.), Un continente en movimiento: Migraciones en América Latina, Iberoamericana / Vervuert, Madrid / 
Frankfurt, pp. 433-450. 2006.

VIOR, E. (2006b), “Los derechos especiales en la Constitución de 1949 desde una perspectiva intercultural de los derechos humanos", en: H. E. Biagini y A. A. Roig (dir.), El pensamiento alternativo en la Argentina del siglo $X X$ - Tomo II: Obrerismo, vanguardia, justicia social (1930-1960), Buenos Aires, Ed. Biblos, pp. 191-208.

VIOR, E. (2007a), “¿Cambia la visión de los derechos humanos de una cultura a otra?", en: Lértora Mendoza, C.A. (coord.), Evolución de las ideas filosóficas 1980-2005. XIII Jornadas de pensamiento filosófico, FEPAl, Buenos Aires.

VIOR, E. (2007b), “Migración, derechos humanos y orden político desde una perspectiva intercultural", en: Alemián, C. (coord.), Las ideas del Siglo XXI. XII Jornadas de Pensamiento Filosófico, FEPAI, Buenos Aires, pp. 209-223.

VIOR, E. (2007c), “Die politische Partizipation von Migranten stärkt die Demokratie - Fallstudie: die bolivianische Minderheit in Argentinien", en: Berger, Lena et al. (Hrsg.), ¿Sin fronteras? Chancen und Probleme lateinamerikanischer Migration, München, MartinMeidenbauer-Verlag, pp. 49-72. ISBN 978-389975-634-0.

VIOR, E. (2008a), “El derecho humano a la migración y las ciudadanías interculturales emergentes: el caso de la minoría de origen boliviano en la Ciudad de Buenos Aires», ponencia presentada en la Mesa de trabajo: "Antropología de las migraciones contemporáneas en la Argentina”, 'Comisión 3: Acciones colectivas y dinámicas identitarias de los y las migrantes' (Coordinador: Roberto Benencia). Actas. $X$ Congreso de Antropología Social: Fronteras de la Antropología, Posadas, 7 de agosto, CDRom, ISBN 978-950-579-103-3.
VIOR, E. (2008b), Arts. sobre "Derechos culturales" (pp. 153-155) e "Inmigrante” (pp. 293295) en: Hugo E. Biagini y Arturo A. Roig (dir.), Diccionario del Pensamiento Alternativo, Buenos Aires, Lanús, Biblos, UNLa, ISBN 978-950786-653-1.

VIOR, E. (2008c) “Una visión intercultural de los derechos humanos para estudiar Argentina desde la Ciencia Política“, en: Guerci de Siufi, B. (comp.), Filosofía, cultura y sociedad en el NOA, S.S. de Jujuy, Ediunju, pp. 45-51, ISSN $\mathrm{N}^{\circ}$ 0327-1471.

VIOR, E. (2008d), "El derecho humano a la migración y el libre ingreso de sudamericanos al país modifican la teoría y la acción políticas“, en: Bazzano, B; D“Andrea, V. y Arué R. (comp.), Jornadas nacionales Transformaciones, prácticas sociales e identidad cultural, Tucumán, Proyecto CIUNT H333 - Instituto de Historia y Pensamiento Argentino, ISBN N ${ }^{\circ} 978$ 950-554-559-9, tomo II, pp. 744-758.

VIOR, E. (2009), “Participación ciudadana en las comunidades de origen inmigrante en la provincia de Río Negro"; Nuevo espacio públiCo, N $\mathrm{N}^{\circ} 2 / 3$, pp. 165-198.

VIOR, E. (2010), "El derecho humano a la migración y la ciudadanía intercultural en zonas de frontera intercultural", en: Fornet-Betancourt (Hrsg.), Alltagsleben: Ort des Austauschs oder der neuen Kolonialisierung zwischen Nord und Süd. Aachen, Wissenschaftverlag Mainz, pp. 357-379.

ZAMBRANO, M. (1990), Los Bienaventurados. Madrid, Siruela.

SITIO WEB de Dra. Alcira Bonilla y Dr. Eduardo J. Vior. DERECHOS HUMANOS, MIGRACIÓN Y PARTICIPACIÓN, www.ddhhmigraciones.com.ar 